\title{
Los motines en la Gobernación de Alicante en abril de 1766
}

CARlos E. Corona Baratech

Universidad de. Zaragoza

\section{El estado de la cuestión}

El motín contra el Marqués de Schilace, D. Leopoldo de Gregorio, a quien se llama siempre Esquilache de acuerdo con la grafía de su pronunciación, ministro del Rey Carlos III, ocurrido en Madrid durante la Semana Santa, desde el Domingo de Ramos, 23 de marzo, hasta el Jueves Santo, 26 siguiente, de 1766, ha suscitado el interés de los historiadores en los últimos años. Pasó a la Historia como «el motín de las capas y de los sombreros», pero, una vez iniciado, los tumultuarios exigieron la baja de los precios'de los abastecimientos. A continuación se multiplicaron los desórdenes, algaradas, tumultos, asonadas y motines (nombres utilizados en la documentación del tiempo) por todas las regiones de la Península.

El motín matritense se ha identificado como protesta nacional contra el gobierno de un extranjero que quiso privar a los españoles del uso de su indumentaria «tradicional», la capa larga y el sombrero redondo con ala ancha; sin embargo, la humilde representación que ha- 
ce a vuestra magestad el motín matritense descubriendo el motivo que obligó a sus fieles corazones, a hacer lo que hicieron..., lo desmiente. La causa del motín o, con más propiedad, del movimiento político, fue otra, y el Bando del 10 de marzo de 1766 prohibiendo tales prendas, solamente el pretexto:

Atribúyese éste al precepto de las Capas y sombreros. Este preparó el alto fin que se deseaba, pues los interesados de la observancia no miraban los estados felices o infelices de la monarquía, ni su restablecimiento, sólo sí aquella aparente conveniencia de la que se creen privados; son necesarios en estos intentos, pero gobernaba más alto fin los corazones. Buena prueba es el modo con que se han ejecutado; pues, una Corte desordenada que a la vista guarda toda la equidad que en serenidad puede desearse, ¿no está diciendo el fiel con que se pesaba la mas mínima acción? '.

Los motines de las provincias se consideran todavía como motines de subsistencias, tomándolos según el modelo estudiado por autores extranjeros en los países al norte de los Pirineos ${ }^{2}$ y separándolos totalmente del matritense ${ }^{3}$.

La tesis sostenida sobre los motines provinciales subraya las características siguientes: a) fueron alzamientos de protesta popular surgidos espontáneamente por el hambre, debida a la falta de granos, y por el alza de precios de los abastecimientos; b) la espontaneidad rechaza una

1 De la Humilde Representación... abundan las copias en manuscritos como Discurso histórico de lo acaecido en el alboroto ocurrido en Madrid..., en la Bibl. de la R. Academia de la Historia, 9/5879, E/64, x. 155 y Causas del motín de Madrid, en la misma Biblioteca, sig. 9/5973, E/158, x. 87; copia del primero se halla en la biblioteca particular de D. Joaquín Gil Marraco, de Zaragoza, Papeles varios, t. I; en la Bibl. Universitaria de Barcelona, «Miscelánea política», A, 168-236, n. ${ }^{\circ} 5$. En la Catedral de Valencia, en «Especies perdidas» de Pahoner, t. X, ff. 345-349. C. CORONA, «Sobre el tránsito del absolutismo al liberalismo en España», Cuadernos de Investigación, Colegio Universitario de Logroño, $\mathrm{n} .^{\circ} 2,1975$, páginas 63-82.

2 Louise TILLY, «El motín de subsistencias como forma de conflictos políticos en Francia», Rev. de Occidente, $\mathrm{n} .^{\circ} 122$, mayo 1973, pp. 208-248.

E. P. THOMPSON, «La economía moral de la multitud en la Inglaterra del siglo XVIII», Rev. de Occidente, n. ${ }^{\circ} 133$, abril de 1974, pp. 54-125.

J. HOBSBAWN, Rebeldes primitivos, Barcelona, 1974.

G. RUDE, Protesta popular y revolución en el siglo XVIII, Barcelona, Ed. Ariel, 1978.

3 J. NA VARRO LATORRE, Hace doscientos años. Estado actual de los problemas históricos del motín de Esquilache, Madrid, Inst. de Estudios Matritenses, 1966. P. VILAR, «El motín de Esquilache y las crisis del Antiguo Régimen», Rev. de Occidente, n. ${ }^{\circ} 107$, febrero 1972 , pp. 199-249.

Laura RODRIGUEZ, «El motín de Madrid» y «Los motines de 1766 en provincias», en Rev. de Occidente, n. ${ }^{\circ} 121$ y n. ${ }^{\circ} 122$, abril y mayo de 1973 , pp. 29-49 y 183-207 respectivamente. 
relación previa, salvo el reflejo de los ejemplos de Madrid o de lugares próximos; c) no fueron el efecto de un movimiento político determinado, ni mucho menos dirigido. No hay disparidad de criterios respecto del primer punto y del segundo; se muestra alguna reserva respecto del segundo y un enfoque distinto en el caso particular de Elche (Ruiz Torres).

El estado de las investigaciones permite dudar de la espontaneidad y del origen popular del movimiento subversivo general. Decir alzamiento popular o motín propiamente lleva consigo la afirmación de alzamiento espontáneo, que se produce en una situación y en un momento crítico concreto, sin preparación previa y sin recursos previos, pero que logra la inmediata adhesión popular para protestar de la equivocada conducta de una autoridad local, por lo general sobre abastecimientos, que se ve obligada a ceder, siquiera temporalmente, hasta que refuerza sus recursos para la represión. Los motines de abril de 1766 presentan superficialmente por sus manifestaciones ruidosas estas mismas características. Los datos extraídos de la documentación consultada ofrecen otros aspectos que es necesario tener en cuenta para la valoración más ajustada de los hechos. Entre los problemas que presenta la investigación histórica, el propósito de conocer los sucesos del pasado, lograr su descripción en su totalidad, comprenderlos e interpretarlos; dentro de su propia realidad temporal, puede semejarse al propósito de describir el interior completo de una habitación cuyo contenido y proporciones se desconocen, mirando tan sólo por el ojo de la cerradura de una puerta. Con seguridad podrá tenerse como cierto lo que el espectador describe de la parte de la habitación que puede contemplar, pero podrá ser objetado total o parcialmente por otro observador que vea el mismo interior desde un ángulo diferente y lo describa con no menor exigencia de verdad. Ambos dicen una parte de la verdad del interior que contemplan aunque parezcan contradictorios.

El Dr. Rodríguez Casado en sus primeros trabajos sobre el reinado de Carlos III razonó una nueva perspectiva sobre el motín de Madrid, que me despertó el deseo de seguirla cuando llegó a mis manos el relato oficial del motín de Zaragoza redactado por Sebastián Latre muy poco después de los sucesos. La tesis doctoral del Dr. Egido y sus posteriores investigaciones y trabajos han aclarado y levantado cuestiones de primera importancia sobre tendencias políticas y políticos del reformismo borbónico, relativas también al motín matritense. Resultado de ello es la necesidad de considerar el fenómeno de los motines de 1766 en un 
cuadro de problemas en el que las capas, los sombreros y el hambre tengan la significación que les corresponde en su momento ${ }^{4}$.

\section{Observaciones generales sobre los motines}

En la documentación conservada sobre el motín de Madrid y sobre otros posteriores se encuentran informaciones que no se han tenido en cuenta o han sido desestimadas: «El motín mas famoso que se lee en las historias ha sido éste [el de Madrid], donde todos iban a una y no hubo hurto alguno [...] En el motín anda gente de grande juicio», escribió un autor anónimo en una Carta [que] va sin firma por si acaso la cogen»" «Referiremos las determinaciones de los Alborotadores, que por ser tan cautas y tan diestras estamos por creer que concurrieron a su práctica algunos sujetos verdaderamente instruidos», dice también otra Relación anónima: «Este golpe fue, sin dificultad dirigido por mano bastante grande». La Relación recoge la carta dirigida al Rey Carlos III, ya huido a Aranjuez, con un estilo totalmente extraño a la mentalidad popular: «En este concepto, Señor, los humildes Vasallos que han mantenido el Alboroto de esta Corte, juntos todos y de común acuerdo hacen

4 V. RODRIGUEZ CASADO, «Política interior de Carlos III», Simancas, I, 1950; «Revolución burguesa del siglo XVIII español», Arbor, n. ${ }^{\circ} 18,1951$, pp. 5-30; Política y políticos en el reinado de Carlos III, Madrid, Rialp, Bibl. del Pensamiento Actual, n. ${ }^{\circ} 113,1962$.

Teófanes EGIDO, «Motines de España y proceso contra los jesuitas», Estudio Agustiniano, vol. XI, fasc. II, 1976, pp. 219-260, y «Oposición radical a Carlos III y expulsión de los jesuitas», Bol. R. Academia de la Historia, CLXXIV, cuad. III, pp. 529-545.

C. E. CORONA, «El motín de Zaragoza del 6 de abril de 1766», Zaragoza, n. ${ }^{\circ} 14,1961$, pp. 197-228; «El poder real y los motines de 1766», Homenaje al Dr. Canellas, Zaragoza, Fac. de F. y Letras, 1969, pp. 259-277; «Sobre el tránsito del absolutismo al liberalismo», Cuadernos de Investigación, Logroño, n. ${ }^{\circ} 2$, 1975, pp. 63-82; «Los sucesos ocurridos desde marzo a mayo de 1766 en Tobarra, Oviedo, Totana, Quesada y Liétor», Cuadernos de Investigación del Col. Univ. de Logroño, t. III, fasc. 1 y 2, 1977, pp. 99-120; «Los sucesos de Sevilla y Jaén en abril de 1766», Hispania, n. ${ }^{\circ} 37,1977$, pp. 541-568; «Los sucesos en Badajoz el 7 de abril y en Baza el 25 de mayo de 1766», Homenaje al Dr. Frutos, Fac. de F. y Letras de Zaragoza, 1977, pp. 93-104; «Los sucesos en Palencia en abril de 1766», en Cuadernos de Investigación Histórica, Fundación Universitaria Española, número 3, 1979, pp. 35-54; «La spontaneité des émeutes et soulévements populaires en Espagne en 1766 y 1808 », en $L^{\prime}$ Information Historique, n. ${ }^{\circ} 5$, nov.-dec. 1979, pp. 218-219; «Los “Cuerpos” de Zaragoza según el Marqués de Avilés, Intendente de Zaragoza en 1766»; «El problema de la jurisdicción de los Intendentes», Cuadernos de Historia, n. ${ }^{\circ}$ 37-38, Zaragoza, Inst. Fernando el Católico, 1980, pp. 96-116.

5 Archivo General de Simancas, Gracia y Justicia, leg. 1009, n. 581. 
a V.M. esta Reverente Representación para que no ignore V.M. los motivos que les asistieron para esta determinación ${ }^{6}$. El Intendente de Badajoz comunicó al Conde de Aranda, con bastante posterioridad a los sucesos en aquella ciudad, que le habían enviado un anónimo insinuándole que «había una Conjuración de sujetos de poder resueltos a hacer conmigo un atropellamiento y expresándome viviese cautelado y con atentas precauciones, porque tal vez sería autor y ejecutor el que tuviese yo por amigo ${ }^{7}$. Sobre el motín de Guipúzcoa escribía Lariz a su primo Fernández de Larios: "dicen aquí que el motín de ésa ha dimanado de arriba» ${ }^{8}$. El pasquín que anunció el abortado motín de Jaén comenzaba así: «Viva España. Ya murió Esquilache. De Orden comunicada del nuevo Congreso con quien cierto número de vecinos de esta Ciudad estamos incorporados y juramentados a guardar los Capítulos que previene su Cristiana Institución, nos es comunicada facultad, en fecha 9 del corriente, en un Orden para que pidamos...» al Intendente las bajas de los precios de los comestibles ${ }^{9}$. Este es el testimonio más claro y concreto sobre el origen y centro de una conjuración, hasta el extremo de citar la fecha de la orden. La carta anónima dirigida al Corregidor de Villena lo señala también: "Lo que pedimos es que cierren las tiendas y las tabernas y que se dé el Pan a razón de lo que está en Alicante y si no se le quitará el Pellejo y se ordena en Madrid ${ }^{10}$.

$13 / 2$

No me refiero ahora a las «Constituciones y Ordenanzas [...] para el nuevo Cuerpo que en defensa de la Patria erigió el amor Español», que dejamos para más adelante. La existencia de estas Constituciones y la referencia al Cuerpo, cuyos antecedentes descubrió el Dr. Egido, llevan de la mano a considerar sus posibles relaciones con la serie de motines que se fueron escalonando desde el 31 de marzo, en Tobarra, hasta finales de mayo y principios de junio siguientes por diversas regiones, a

6 Se trata de la Humilde Representación citada en la nota 1.

7 Archivo Hist. Nacional (AHN), Consejos, leg. 17802, X, el Intendente Sebastián Gómez de la Torre a Aranda, Badajoz, 28 de abril de 1766.

8 AGS, GJ, 1009, 547, sin fecha.

9 AHN, Cons., leg. 418/2, 20-27, Testimonio del escribano Luis Borbón y Mora, del 22-IV-1766. Hay otra copia en el f. 50 y ss.

C. E. CORONA, «Los sucesos de Sevilla y Jaén», cit. nota 4.

10 Carta al Corregidor Pedro Alejandro de Ribera, del 28 de abril de 1766, en auto del escribano Joaquín Valero y Thomas del 12 de mayo de 1766, AHN, Cons. leg. 17801, XXVII.

J. M. PALOP, en o. c., nota 3, reproduce el texto de L. RODRIGUEZ en «Los motines de 1766 en provincias», p. 194, mal leído: «se le quitará el pellejo y se pondrá en Madrid». 
veces simultáneamente ${ }^{11}$. Laura Rodríguez ha reseñado 69 lugares; por mi parte, fueron más de 120 los que en grado muy diverso quedaron afectados por el movimiento, si bien entre ellos se cuentan las aldeas o caseríos de donde procedían muchos condenados en los procesos seguidos en Guipúzcoa, los de Aragón y los de los señoríos del Duque de Arcos y del marquesado de Dos Aguas ${ }^{12}$.

Con posterioridad al 16 de junio, fecha del alboroto de Villar de Olalla, no se encuentran noticias de otros análogos, aunque el 8 de agosto amenazó uno que era consecuencia de las prisiones hechas por los motines de Elche y Crevillente. No se trataba ya de rebajar los precios del pan y de otros artículos de consumo alimenticio: aceite, jabón, vino, aguardiente, carne de vaca o de oveja, el maíz, las legumbres, etc., según cada lugar. Las disposiciones reales y del Consejo de Castilla anularon el éxito de lo que parecía ser el objetivo de los motines. La Pragmática del 5 de mayo restableció los precios rebajados por las autoridades de cada lugar y amenazó con penas más severas. Anteriormente, la del 14 de abril contra la publicación de pasquines, sátiras, panfletos y otros escritos de la misma especie, y contra sus autores y los que los difundían, moderó el número, pero no los suprimió radicalmente.

La variedad de circunstancias peculiares en las ciudades, villas y pueblos afectados presenta un repertorio de cuestiones interesantes. Afloran los problemas sobre la política reformista del siglo ilustrado. La concepción jurídica del Estado ilustrado, absoluto pero paternalista, llevaba consigo la destrucción de un orden histórico de privilegios estamentales y habría de suscitár, y de hecho provocó, una reacción gradual manifestada por vías y sectores sociales distintos a lo largo del siglo ${ }^{13}$.

El análisis de los tumultos ocurridos en algunas ciudades es una necesidad que no puede cumplirse en las líneas que siguen, pues en ellos se reflejan aspectos distintos de los problemas económicos, administra-

11 T. EGIDO, Opinión pública y oposición al poder en la España del siglo XVIII (1713-1759), Valladolid, Universidad, 1971, 354 págs.

12 Actualmente estoy redactando el resultado del estudio de todos los tumultos en el que los ya publicados y este mismo que comentamos recogerán el concepto general que de ellos se desprende.

13 Vid. C. CORONA, «Sobre el tránsito del absolutismo al liberalismo», cit. en nota 1 , pp. 68 y ss. 
tivos y hasta religiosos de la política del momento ${ }^{14}$. El punto de partida de los motines y asonadas fue casi siempre el mismo: la aparición de pasquines y de cartas anónimas dirigidas a las autoridades del lugar correspondiente. Su contenido induce a llegar a una comprensión del movimiento que, por la identidad de características, se califica de revolucionario.

\section{Análisis de los pasquines o «papelones»}

Casi todos los Intendentes, Corregidores, Alcaldes Mayores o Cabildos Municipales se apresuraron - algunos esperaron demasiados días para hacerlo- a enviar al todavía Gobernador del Consejo D. Diego de Rojas, Obispo de Cartagena; a D. Manuel de Roda, Secretario de Gracia y Justicia y Superintendente General de los Pósitos, y al Conde de Aranda, Presidente del Consejo y Cámara de Castilla desde su nombramiento el 9 de abril sustituyendo a D. Diego de Rojas, los informes sobre las alteraciones que se iban produciendo. Roda guardaba a veces copia del pasquín, antes de trasladarlo a Aranda.

En otros casos el texto de los pasquines aparece reproducido en los testimonios redactados por los escribanos del lugar a petición de las autoridades municipales para enviarlos al Consejo o para incorporarlos a los procesos contra los inculpados. De algunos pueblos o villas se da la información de que se fijaron pasquines, como en los pueblos de Aragón Barbastro, Estadille, Fonz, Monzón, Daroca, Calatayud, Alcañiz, o como Soria, cuyo Corregidor no les dio importancia y no los recogió ${ }^{15}$.

La fijación de los pasquines era el aviso de la algarada para las autoridades y la llamada de alerta para la población. La respuesta dócil y anticipada al plazo dado en el pasquín para rebajar los precios detenía el motín o lo anticipaba (Zaragoza, Cuenca). Se daba también la fórmula de provocar una situación o aprovechar un pretexto, congregado ya el pueblo, para solicitar la baja de los precios. Así puede apreciarse en los casos de Badajoz y de Baza: sacar un Víctor para aclamar

14 Respecto de los jesuitas vid. T. EGIDO, «Motines de España y proceso contra los jesuitas", citado en nota 4 y en colaboración con Jorge CEJUDO, Pedro Rodriguez de Campomanes, Dictamen fiscal de expulsión de los jesuitas de España (1766-1767), Madrid, Fundación Universitaria Española, 1977, donde se aportan datos de primera importancia para comprender el espinoso problema de la expulsión.

15 AHN, Cons., leg. 1193/1, 2. a parte, ff. 92-98, y en el leg. 17801 , n. ${ }^{\circ} 31$, escritos del Marqués de Castelar, de Zaragoza, del 12 y 13 de abril. 
a D. Gregorio de Muniáin, promovido a Secretario de Guerra del gobierno de Carlos III; sacar otro Víctor en Baza para aclamar a un fraile franciscano anciano y jubilado. En Sevilla, la provocación era el encierro en la iglesia del convento de San Francisco de 500 soldados que reclamaban pagas no satisfechas. En Palencia, la indignación de los obreros tejedores porque los patronos los llamaron borrachos y holgazanes; en Tobarra, la introducción de trigo en el Pósito por un negociante ${ }^{16}$. La fórmula más utilizada era convocar al pueblo mediante el toque de alarma general a campana repicada al atardecer o ya entrada la noche. Esta era la fórmula más eficaz, pues nadie quedaba insensible al toque de fuego o de alarma.

Los alborotos continuados día a día desde el $\mathbf{3 1}$ de marzo durante el mes de abril y en el mes de mayo fueron prontamente valorados por el Rey y sus ministros. Como ya se dijo anteriormente, el Auto Acordado del 14 de abril prohibió y condenó los pasquines, sátiras, versos, manifiestos y otros papeles injuriosos a personas públicas o a cualquier particular ${ }^{17}$. La orden del Rey al Conde de Aranda, del 21 de abril, para hacer la «pesquisa secreta» revela que se tenía conciencia de que había ciertos promotores del movimiento revolucionario:

Han continuado las sátiras, manifiestos sediciosos y otras composiciones de esta naturaleza. Por la calidad de estos papeles sediciosos y puntos que tocan, se percibe con toda claridad que esta cizaña no dimana del Pueblo de Madrid, antes se reconoce en todas las clases la más perfecta quietud [...] y respeto a la justicia, si se exceptúan los incógnitos que forman, esparcen y siembran otras especies que trascienden a las Provincias y hacen odioso al gobierno, suponiendo vejaciones y descontentos en mis Dominios de las Indias, contra la verdad de los hechos, habiendo dado cuerpo a las conmociones experimentadas en otros Pueblos, estas especies vertidas al mismo tiempo como un efecto de los papeles sediciosos divulgados... ${ }^{18}$.

Recién publicado el A. Acordado prohibiendo los pasquines, se fijó en Madrid, el 17 de abril, la réplica llamada Contra-Bando, que dio lugar al proceso Baranchán-Navarro, muy sonado, que sirvió para arrojar la responsabilidad a los jesuitas:

A todos los habitantes de Madrid. Nos sus Tribunos, por la gracia de la Plebe: En vista de lo respondido por el nuestro Fiscal en pleno Tribunal, juntas las Cámaras de LAVAPIES, BARQUILLO, MARAVILLAS Y RASTRO, MANDAMOS la inobservancia de el BANDO ayer publicado sobre prohibición de Papeles relativos a los motines y resultas de nuestro pasa-

16 C. E. CORONA, vid. «Los sucesos en Badajoz y Baza, Sevilla y Jaén, Palencia, Tobarra...», nota 4.

17 Novísima Recopilación, L. 8, tít. 25, Lib. 12.

18 AGS, GJ, leg. 1009, Aranjuez, 21 de abril de 1766, El Rey a Aranda. 
do MOVIMIENTO por ser intempestivo, contrario a las Leyes e indecoroso a nuestras personas y la SAGRADA DEL SOBERANO, como en su respuesta manifiesta el Fiscal y verá el Pueblo. Abril 17 de 1766 . [Está rubricado] ${ }^{19}$.

La alusión a nuestro pasado Movimiento es contundente y sobre ello hay suficientes testimonios que dejan en muy segundo plano la tesis sobre las capas y las subsistencias. No trataré ahora del motín de Madrid, sino de los presuntamente espontáneos surgidos en las provincias contra el alza de los precios del pan, de la sidra (Guipúzcoa), o del pescado (Palencia), etc. Contemplados aisladamente y según los matices peculiares que se enmascaran en cada lugar, podría creerse en la espontaneidad ante el hecho real de las crisis agrarias del siglo y la subida de los precios en los llamados meses mayores anteriores a la cosecha siguiente. En Salamanca la cosecha se consideraba gravemente amenazada en el mes de marzo, pero no ocurrió así. Considerados en conjunto los sucesos repartidos por todas las regiones españolas, hay unas notas comunes y significativas reflejadas en los pasquines y en el desarrollo de los hechos.

\section{El contenido de los pasquines}

Los textos de la mayor parte de los pasquines recogidos y las noticias sobre otros inclinan a pensar en una misma fuente inspiradora de normas comunes que guardan relación con el motín de Madrid.

El tema general lo constituye la baja de los precios de los abastos, el del pan especialmente como alimento básico de la dieta alimenticia de los pueblos, aunque el enriquecimiento de la dieta es general en Europa. La convocatoria tendría siempre efectos positivos en la tendencia inflacionista de los meses mayores. El Fiscal del Consejo don Pedro Rodríguez Campomanes informaba el 4 de mayo, con las noticias llegadas de Palencia: «La baja de los abastos es cantinela común, como el Fiscal lo observa en los demás Pueblos del Reino, [...] es de recelar que las gentes mal intencionadas hallen modo de poner en conmo-

19 Memorial ajustado que a instancia del Ilm. ${ }^{\circ}$ Sr. D. Pedro Rodríguez Campomanes, fiscal del Consejo y en virtud de Decreto extraordinario de 21 de diciembre de 1766 ha sustanciado, en calidad de Comisionado el Señor don Agustín de Leyza, del Consejo de S. M. en el de Hacienda, sobre la voluntaria delación que en 28 de octubre de 1766, hizo al Excm. ${ }^{\circ}$ Sr. Conde de Aranda por escrito y firmada de su mano el Doctor don Benito Navarro, Abogado de los Reales Consejos, suponiendo que D. Juan Baranchan era el autor del papel titulado El Contrabando y otros satíricos... En Madrid, por Joaquín Ibarra, 1768. 
ción al Común arbitrariamente ${ }^{20}$. Por esto no es de extrañar que en algunos procesos se encuentren mujeres encausadas (Cuenca, Palencia, Albatera), aunque no fue general.

El segundo tema se refiere a las amenazas a las autoridades locales: Intendentes, Corregidores, Alcaldes Mayores u Ordinarios, Depositarios o Agentes que tenían a su cargo los Pósitos. Puede constatarse en los siguientes pueblos y ciudades: Bujalance, Granátula, Tobarra, Zaragoza, Cuenca, Sevilla, Borja, Codo, Cartagena, Orihuela, San Sebastián, Honrubia, Madrid, Iniesta, Hervás, Granada, Quero, Jaén, Mancha Real, Burgos, Aramayona, Palencia, Guadalajara, Oviedo, Totana, Quesada, La Coruña, Liétor, Salvatierra, Benabarre, Soria, Membrilla y Baza. No se citan otros porque de ellos solamente hay noticia de pasquines, pero no de su contenido.

A las autoridades se agregan ciertas personas particulares por ser beneficiarios, probablemente o con toda seguridad, de la política del gobierno o por su provechosa relación con las antedichas autoridades locales: así se observa en Tobarra, Zaragoza, Salamanca, Cuenca, Sevilla, Cartagena, Orihuela, San Sebastián, Iniesta, Lorca, Granada, Burgos, Mancha Real, Palencia, Granátula, Oviedo, Membrilla, La Coruña y Baza. En Salvatierra de Alava se amenaza al "Chanfutre de el Gallego» y el «burro de Jeromo»; en Membrilla, «al Culebro», a «Doña Jacinta», a «Doña Josefa» y al «Cura Santo, que no es sino el Demonio»r.

Las amenazas son de muerte sin especificar, como en Burgos, La Coruña, Salamanca, Totana; por decapitación, en Baza, Membrilla; en Zaragoza, con la cabeza clavada en un palo en el campo de Toro; «atado a una estaca», en Granátula; «arderás con los Demonios», dice el pasquín de Bujalance; «se le quitará el pellejo», en Villena; «quemado y frito en aceite hirviendo», en Cartagena. Se añade el incendio de las casas y quemar a los amenazados en Baza, Bujalance, Membrilla, Salvatierra, Zaragoza, Alicante, etc... Ciertamente, las acusaciones que se hacen a las autoridades y a los particulares son las comunes en todos los tiempos y lugares: logreros, ladrones o hambrones; así en Baza, Bujalance, Membrilla, Salvatierra, Zaragoza, Burgos y La Coruña. La temática de los pasquínes es la misma en todos los lugares; es intemporal y universal con recursos elementales para sensibilizar rápida y fácilmente a la masa popular. ¿Quién se atrevería a oponerse a que se bajen los precios de los comestibles? ¿Quién no uniría su voz a las de los que piden que sean más baratos?

20 Vid. C. E. CORONA, «El poder real y los motines de 1766», cit, nota 4. 
El punto tercero es el grito común de ;Viva el Rey! ;Abajo el mal gobierno! La acusación por todos los males que sufren los pueblos salva siempre la figura carismática del Monarca, cumpliéndose la tradición de arrojar las culpas sobre sus ministros y contemplar al Rey inocente. Se nombra en algunos pasquines a Esquilache, como en Jaén: "Ya murió Esquilache», pero siguen las órdenes dadas por Esquilache y éstas son las que deben ser modificadas. En ámbitos locales se acusa a los Esquilaches locales, beneficiarios o no de las consecuencias de esta política general. El Rey y el mal gobierno son los centros de la acción tumultuaria: el Rey porque de él solamente se esperan bienes y protección para el Pueblo; el mal gobierno es el que existe y se ha heredado de los tiempos anteriores.

El punto cuarto que se repite constantemente es la fijación de un plazo para que se cumplan las peticiones que se hacen en los pasquines. El plazo es variable desde un día (en Tobarra) hasta ocho días que no se cumplen porque los motines se adelantan o porque se detienen por la prisa de las autoridades en concederlas. En este caso, sin embargo, el deliberado proyecto de llevar adelante la asonada provoca mayores exigencias hasta producirse la ruptura. Se dieron plazos en Madrid, Bujalance, Zaragoza, Cuenca, Barcelona, San Sebastián, Iniesta, Granada, Lorca, Jaén, Mancha Real, Aramayona, Oviedo, Totana, Salvatierra y Membrilla.

El punto quinto se refiere al cumplimiento de las amenazas, advirtiendo que se dispone de hombres o de fuerzas para tomar las represalias: 200 hombres en Baza, 700 en Eibar, 2.000 en Azcoitia, 790 en San Sebastián, 1.000 en Madrid, 60 y 80 en Membrilla, hombres preparados en Granada y Quesada, en Sevilla se dice de una diputación de 50 hombres, en Aramayona se advierte que acudan con armas.

A las vista de unas manifestaciones que son las mismas en los pasquines de distintas ciudades y en lugares alejados entre sí y de fechas sucẹsivas, no puede excluirse la difusión de unas mismas normas distribuidas por el mismo equipo de personas a quienes habían de seguirlas en cada ciudad. El Intendente de Badajoz decía que «había una conjuración de sujetos de poder»; el pasquín de Bujalance alude a «mis compañeros»; el de Burgos, a «los audaces» cuya «ocasión nos ha llegado»; en Granada, «haberse dado por la expresada vía de Hacienda, facultades de hacer y deshacer en todo lo perteneciente a la utilidad pública»; los de Salvatierra advierten al Regidor «si no me enojaré con otros» y al Procurador «la machinada no será ahora, después será»; el de Villena se atreve a ser más explícito: «y se ordena en Madrid». El Alcalde Ordinario de Granátula, Pedro Pablo López Carretero, es amenazado de 
muerte «porque conviene». A pesar de las amenazas, no hubo más que algunos daños materiales en los bienes, pero nada en las personas físicas, de acuerdo con las Ordenanzas del Cuerpo Nacional.

Los pasquines más elocuentes son los de Jaén y de San Sebastián. El de Jaén dice lisa y llanamente a quién obedece y la fecha de la orden:

Viva España. Ya murió Schilace.-Por Orden comunicada con quien cierto número de vecinos de esta Ciudad estamos incorporados y juramentados a guardar los capítulos que previene su Christiana Institución, nos es comunicada facultad en fecha del nueve del corriente en un Orden, para que pidamos a D. Vicente Caballero Yllanes, nuestro Juez por el Rey Nuestro Señor a quien veneramos, nos haga partícipe de los favores, gracias y privilegios que S.M. (que Dios guarde) ha concedido a nuestra Capital y Corte, es a saber: el Pan a 20 mrs. / La oveja a $24 \mathrm{mrs}$. / Carnero a $18 \mathrm{mrs}$. / Aceite y Jabon a 34 mrs. / Semillas, 4 mrs. menos en Libra./ - En el particular de Millones, menos tiranía, haciéndose cargo de la estrechez. Cobranza de las extraordinarias contribuciones, suspensión por ahora, dándose para esto término de 3 días, para que consultado con los Diputados de esta Ciudad se efectúe; y de lo contrario obedeceremos lo que se nos mande por el nuestro Congreso, sin faltar a ninguno de los Capítulos que por su Orden se previenen; llevando por delante la Santa Fé Cathólica, defensa de nuestro Rey y alivio de sus vasallos, a cuyo fin se dirige el citado nuestro Congreso. Del pedimento concedido se remite testimonio a nuestro Congreso. Expiraron las órdenes de Schilace.

Convocatoria. Vecinos de Jaén, vasallos de nuestro Rey Carlos Tercero, Dios le guarde.

Sabed nuestra pretensión que dada al público está. Mirad el fin que llevamos, pues en él no se halla ninguno que se dirija contra nuestra santa Ley y lealtad a nuestro Rey. Por tanto a la voz que sonare de Viva España, que será el 22 del corriente asistiréis a dar auxilio a nuestro Congreso, porque así conviene para la reformación de las órdenes dadas por Schilace. [Hay cuatro rúbricas] ${ }^{21}$.

En el pasquín lo de menos es el tema de las rebajas de precios. Ofrece un programa político elaborado por un Congreso al que obedece y da cuenta. Hay vecinos incorporados y juramentados a la cristiana Institución, a la que me referiré más adelante. Se trata de deshacer todo lo hecho por Esquilache. Obsérvese que escribe Schilace con la grafía italiana; no es de mano popular, sino culta. Las referencias a Esquilache son frecuentes. En el siguiente pasquín de San Sebastián, también las hay, así como algunas cuestiones de política general:

¡Oh, Señores Hermanos de mi alma! Con desterrar a Esquilache no se acaban todos los males. Sólo aquí en San Sebastián se permiten varios Esqui-

21 AHN, Cons., leg. 418/2, ff. 3 y 50, y C. E. CORONA, «Los sucesos de Sevilla y Jaén...». 
laches y si a éstos no se remedia ya, se condenarán ellos y viviremos nosotros mortificados. Pues, qué mayores enemigos o demonios que los mismos Capitulares de la Ciudad, que en lugar de proveer en Cinco pesos el pan, nos proveen en diez. Y esto se remedia con traer muchos polvos en las pelucas y galones y con acudir a la tertulia de Jacinto. ¡Oh pobres de España! ¿adónde se han arrastrado tus intereses y honores sino a Francia y a Italia? Ellos nos han quitado todo el Comercio de San Sebastián de toda esta Provincia y últimamente todos los empleos de España. Hasta esto llega la sabiduría y la prudencia española, que contra la ley, valor, fidelidad y justicia, a manos masa, un demonio condenado francés y italiano que a un hermano pobre español, pues nuestra bondad o malicia en demasiado peca y nos veremos precisados a xecutar un desatino, si es que no ponen remedios útiles, como lo verán de hoy en ocho días por la nochecer [sic]. Nadie quite este papel pena de vida» ${ }^{22}$.

La xenofobia es otra de las corrientes constantes encontradas por Egido desde Felipe V y que persiste en los motines de 1766 y en años siguientes. En Zaragoza, se señala en uno de los pasquines al Marqués de Castelar, Capitán Gèneral y Presidente de la Audiencia de Aragón, D. Lucas Fernando Patiño Bolognino Visconti, quien lejos de proteger al Intendente-Corregidor le obligó a salir de Zaragoza con escolta, y la tropa que sacó a la calle contempló pasivamente como espectadora los asaltos e incendios que causaron los amotinados. Uno de los once pasquines recogidos de la ciudad decía:

Avisan al señor Corregidor que si por todo el martes que viene no nos tiene rebajado el trigo, cumpliremos con la promesa que se le ha hecho, y a él lo quemaremos en medio del Campo de Toro, pues estamos noticiosos de que no hace nada. El trigo a cinco reales la hanega y el aceite a doce dineros la libra y así todo lo comestible. No dé V.m. lugar a ello, porque le sucederá a V.m. El Marqués de Castelar ha de ser desterrado, si no lo quemaremos también, porque es italiano, al destierro allá con Squilache y toda su familia, y con esto damos aviso.

\section{Otro de los pasquines puestos en Zaragoza es también expresivo:}

El mal gobierno en España / ha reinado y reinará / y esto se remediará / con volver ya por la Patria, / pues no hay razón que se pierda / por no saber gobernarla. / Los pobres gimen, / los que gobiernan triunfan. / Contra éstos no hay justicias: / para los pobres mucha; / la comercia va muy cara, / no se puede aguantar, / luego se han de rebajar / poniéndola en un precio / que lo podamos llevar. / La Patria viva y el Rey / pero no manda la ley / que se gobierne tan mal. / Los que gobiernan roban y mandan, / los usureros vender y atesorar, / y el pueblo gemir y pagar. / El que lo quite pena de excomunión mayor $^{23}$.

22 Arch. de la Diputación de Guipúzcoa, en Tolosa, neg. 6, leg. 24, Auto del escribano Manuel de Arriola en San Sebastián a 14 de abril de 1766.

23 Los dos pasquines en AHN, Cons., leg. 1193, f. 1 al 15. 
Las voces contra el mal gobierno se repitieron en las principales ciudades y pueblos, con lo que se incrementó el temor de Carlos III cuando buscó refugio en Aranjuez. No cabe dudar que la fuerza de la oposición tenía capacidad de organización para promover tumultos. En Valencia aparecieron pasquines en los días 3 y 4 de abril. Uno de los pasquines enviados el día 5 se refería a una caricatura de dos hombres sentados a una mesa. Los dos hombres, con las cabezas levantadas, miraban una pieza de carne que colgaba en alto. De la boca de uno de ellos salía un rótulo que decía: Comamos, y de la del otro, respondiendo: No podemos si no nos levantamos ${ }^{24}$.

La incitación al levantamiento y al motín se encuentra en otros lugares. El Intendente-Corregidor de Burgos informaba de la preparación del ambiente: «En las conversaciones privadas se hablaba con mucha libertad y desacato, hasta decir que para conseguir era el verdadero medio sublevarse»; de Pampliega también comunicaba: "Los vecinos usan de medios y de expresiones violentas para solicitar sus alivios». La villa de Honrubia se expresaba en términos análogos: «Aquí susurran que para que les bajen el pan será preciso usar de la Grita y el Tumulto» ${ }^{25}$.

El escribano de Jaén, al dar testimonio de los hechos, aclaraba: «Decían que si se levantaba el pueblo, luego dirían que no tenían razón, habiendo tanta falta de pan». Esto último era absolutamente falso ${ }^{26}$.

Los Intendentes y los Corregidores de algunas ciudades, al dar noticia del comienzo de las alteraciones, parecen sorprendidos porque en los días anteriores el ambiente era de completo sosiego, sin que nada hiciese sospechar amenaza alguna de alboroto. Tal era el caso de La Coruña, de Sevilla, de Badajoz y de Burgos. No es fácil encontrar testimonios que prueben la organización de los motines, salvo los citados anteriormente en los pasquines. Es en los procesos realizados en los meses siguientes donde se hallan declaraciones de testigos que declaran conexión o dependencia de una instancia superior. En los procesos de Cuenca, promovidos por D. José Moñino, futuro conde.de Floridablanca, se encuentra la declaración de un testigo contra Carlos Collado, receptor

\footnotetext{
24 Arch. del Conde de Campomanes, Fundación Universitaria, leg. 47/7.

25 El Intendente Corregidor Miguel de Bañuelos al Conde de Aranda, Burgos, 20 y 29 de abril, AHN, Cons., leg. 17802. La Villa de Honrubia al Obispo Rojas, 15 de abril de 1766, AHN, Cons., leg. 17801, XVII. Vid. C. E. CORONA, «Los sucesos de Sevilla y Jaén en abril de 1766», cit. nota 4, pp. 541-568.
} 
eclesiástico acusado de ser autor de un pasquín. El testigo afirmó que el acusado le dijo, después de hablar del motín de Madrid, que «en esta Ciudad [Cuenca] no sería flojo el que habría dentro de uno o dos días [el motín de Cuenca fue el 6 de abril] y que en prueba de ello mirase aquellos papeles o pasquines que decían cómo habría tumulto en esta Ciudad»; de los procesos de Cuenca salen otros importantes testimonios, de los que me limitaré a reproducir el siguiente: "Que habían escrito desde la Corte que hicieran lo mismo en Cuenca» ${ }^{27}$.

Afirmar el carácter repentino y la espontaneidad de las algaradas permite a su vez calificar de ligera y apresurada la lectura de los pasquines que tictan las consignas para iniciarlos: "Estuviesen prevenidos con armas para que oído el rumor de los que sabían, acudiesen a los cuatro sitios que tenían prevenidos», decía el de Granada; «Por tanto, a la voz que sonaro de Viva España, que será a 22 del corriente, asistiréis a dar auxilio a nuestro Congreso", decía el de Jaén; y en los de Zaragoza: «Y a la fecha que se tiene comunicada concurran al puesto destinado para ejecutar las extorsiones [...] y pues se mira al bien común obedezcan la voz del que gobierne el tumulto, so pena de vida». Pueden añadirse más textos acerca de lo mismo, pero quedan en reserva para otro momento ${ }^{28}$.

Hay una tendencia clara en la política de Carlos III y de su equipo de ministros ilustrado, que tiene dos líneas de tensión; por una parte, la pugna regalismo y antirregalismo, agudizada en el siglo XVIII por el concepto del poder monárquico, según Bossuet, que agriaba las relaciones entre la Iglesia y el Estado; por otra, la afirmación del poder absoluto, de carácter antiestamental en lo político, no en la significación social, que derivaba a la igualación de la diversidad de vasallos a una misma condición jurídica de súbditos ante el poder real. Habida cuenta de los términos en que se desarrolla el debate por estas cuestiones, la política real tiende a promocionar y favorecer las libertades económicas para el Tercer Estado, lo que se da en llamar política burguesa, restringiendo los privilegios históricos de los estamentos privilegiados. El Rey llegó hasta decidir repartos de tierras entre los campesinos, pero fracasó. Esta política prefiero llamarla populista o popularista. En el movimiento que comentamos está la llamada al pueblo y la convocatoria del pueblo para un movimiento de protesta popular contra la política, no del Rey, que está salvado por las aclamaciones populares, sino de los

27 AHN, Cons., leg. 485/2, pieza 1, reservada, ff. 6-8; Declaración del testigo de la letra A, leg. $485 / 1$, pieza 3, ff. 113-115, ratificación de un testigo 15 de diciembre de 1767 .

28

Vid. nota 12 . 
Esquilaches en las ciudades y pueblos. El grito general es el del pueblo que tiene hambre: es preciso rebajar todos los precios de los comestibles. Si había carestía de alimentos el hambre continuaría, pero no era el hambre sino las rebajas lo que, sin lugar a dudas, atraería la adhesión popular afectiva. A esto hay que añadir otro aspecto común en los motines, iniciado en Madrid, y repetido en otros lugares: la apertura de las cárceles y la liberación de los delincuentes.

En Zaragoza llama la atención el estilo de mandato de uno de sus pasquines, sin relación alguna con el hambre: «Cualquiera Personas aficionadas a sostener los derechos, prerrogativas, preeminencias que por el derecho Civil y de Cortes, público y privado, nos competen contra los crueles enemigos que atesoran los Bienes de los Pobres representados en Christo ${ }^{29}$. Las invocaciones religiosas se encuentran en la firma de otro pasquín zaragozano «Nos la Caridad, el Juicio cristiano y Político Secretario», en Sevilla, en Jaén, en Villena, en Madrid..., hasta llegar en pueblos de Guipúzcoa a grados de depuración increíbles que no es necesario exponer en este momento.

Queda finalmente, como punto muy importante en este programa de investigaciones, hallar la luz que nos dé perspectiva sobre quiénes pudieron ser los que promovieron los tumultos. Proponemos como hipótesis, por el momento rechazada sin argumentación probada, que hubo un centro de dirección situado en la Corte. Se hizo referencia a la «Humilde Representación» al Rey del Motín matritense, para explicar los motivos que lo impulsaron. Junto a ésta hay que poner las «Constituciones y ordenanzas que se establecieron en la corte y villa de Madrid, para un nuevo cuerpo que en defensa de la patria exigió el amor español para quitar y sacudir la opresión en que los ministros extranjeros intentaban violar estos dominios, a más de las actuales extorsiones que se experimentaban en el siniestro gobierno de sus ministerios». Una y otras, han sido nombradas por los historiadores de Carlos III: Ferrer, Danvila y los que se han servido de ellos, pero sin entrar a analizar sus contenidos. No intentaré reproducir ambos textos en su integridad, pero sí algunos de los 15 artículos de que constan las «Constituciones y Ordenanzas», ya que se corresponden con el método de actuación en los alborotos:

1) Primeramente se ha de observar como punto inviolable que ninguno de los Superiores que se elijan o que de nuevo se admitan, puedan recibir a 
Persona alguna que no sea española y no sólo español por nacimiento, mas ha de ser español en celo honroso, desinteresado, fiel y obediente, los cuales han de jurar y prometer en honra de Dios, cuyo nombre es quien exalta este Militar Cuerpo para defensa de la Fé Católica [...] del Monarca nuestro Soberano [...] y de la Patria [...]

3) Que habiéndose establecido este honroso Cuerpo con el principal objeto de abolir y quitar ciertos perjudiciales sujetos de la Monarquía, se calle y cumpla lo que a primera voz se profiera por uno de los Superiores, siguiendo la acción y mandatos de él con precepto inviolable [...]

5) Que si por motivo de la voz o alboroto que se cause pensasen que el Motín, Tumulto o cualquiera otro ruido o estruendo, fuere perjudicial a la quietud y con este motivo se pusiese la Tropa en Arma, haciendo prisiones o cualquier otro estorbo a nuestro Cuerpo, se manda que ninguno sea osado a tomar Armas de fuego para la defensa, antes bien, con fraternal cariño, la hemos de inducir al conocimiento de nuestra Santa Intención para que no nos perjudiquen nuestros proyectos; pero, si cogieren algunos prisioneros y ni el agrado, ni las ofertas no pudieran conseguir la soltura, permitimos usar de los medios más ásperos y violentos con los que se consiga la libertad de los Presos.

6) Que unánimes todos hemos de hacer juramento ante el Santísimo Sacramento a no descubrirnos, aunque llegue el caso de quedar o poner alguno preso, sin que lo podamos libertar, no ha de poder decir ninguna otra cosa que ni sabe, ni tiene noticia de que haya Cabeza o partido para este ruido, sino que oyendo las voces, pareciéndole justas, las siguió para salir de la Tirania y Violencia de habernos puesto como a franceses, bien entendido que serán de nuestra cuenta, interim estuviese en la Cárcel o padeciendo, hijos, mujer y madre, con toda la familia, para que este Temeroso no se acobarde de la empresa de guardar silencio, que es el norte de este proyecto.

7) Que interim llegase este caso o en el mismo lance necesitasen de algún socorro, cualesquiera de nuestros súbditos, se les entregará incontinenti por cualquiera de nosotros, para no dar lugar a que la necesidad obre acciones ruines que pudieran perjudicar al honor de este Cuerpo ${ }^{30}$.

No es admisible dejar marginados o despreciados, si son conocidos, documentos como el anterior, que tuvieron gran difusión por medio de copias manuscritas muy dispersas, y mucho menos elevar a categorías hechos circunstanciales o coyunturales, que por ser ciertos más bien enmascaran que constituyen la esencia misma de los hechos.

La casualidad en la Historia, considerada por Cournot como innegablemente activa, debe ser sometida al análisis crítico lo mismo que el precio del pan, del vino, del aguardiente, la sidra y el aceite. Llamamos casualidad en el lenguaje común aquello que interviene en los hechos

30 En los Manuscritos citados en la nota 1 se da al documento la fecha del 23 de marzo; sin embargo, en el Archivo del Conde de Campomanes, donde se encuentran varias copias, $47 / 7$, una de ellas está corregida con el 12 superpuesto, sin duda por mano del mismo R. Campomanes y me atengo a ésta como válida. 
sin que pueda ser encajado, ni natural, ni racionalmente, en el proceso que se verifica. El método científico de la Historia no tiene por qué coincidir, ni coincide, con el método científico de las ciencias físicoquímico-naturales, según demostró Rickert ${ }^{31}$. En los cinco artículos anteriormente reproducidos parece que se encuentran antecedentes que se repitieron en algunos de los tumultos ocurridos en los meses de abril y mayo de 1766 . Pueden ser rechazados, pero no se puede negar su existencia documentada.

El artículo primero declara la formación de un Militar Cuerpo, lo que podría apoyar la apresurada tesis lanzada para decir que el militarismo es una corriente política surgida en el siglo XVIII, por el simple hecho de que toda la Oficialidad y todos los Jefes del Ejército y la Marina pertenecían a la Nobleza; y se toma la parte, no el todo. El Militar Cuerpo acepta solamente españoles con las cualidades y virtudes que corresponden al noble caballero, sea o no militar.

El artículo tercero exige, ciertamente, el sometimiento a una disciplina de obedencia militar a Superior o Superiores que deciden y mandan. En el texto anteriormente reproducido, el «motín matritense» se envanece del orden guardado en Madrid durante su desarrollo.

En el artículo quinto se indica que no debe llegarse a un enfrentamiento armado con la Tropa, a no ser en último extremo para liberar a los que hubiesen sido apresados, y cuando no se atendiese a su fraternal cariño y Santa Intención. En los motines de Zaragoza, Palencia, Lorca y otros más, las fuerzas armadas, con sus Jefes al frente, conservaron una actitud tan contemplativa que más parecía de pasiva colaboración.

El juramento de secreto es lo que hace más díficil el rastreo de cómplices de categoría superior. Las instrucciones mandadas por el Consejo a todas partes donde se inician las investigaciones sobre los tumultos insisten en la averiguación de los que hubieran sido cabezas del motín y si se hallaban complicadas personas privilegiadas. En Zaragoza se ahorcó rápidamente a un miembro de familia distinguida, cuyo nombre todavía queda vedado, pero en una carta de Aranda se dice que era persona extraña a la ciudad, que se hallaba de paso y por asuntos propios $^{32}$. En Cuenca pareció complicado un regidor, y en Lorca otro hidalgo fue condenado a diez años de prisión. Es curioso el proceso le-

31 COURNOT, Consideraciones sobre la marcha de las ideas y de los acontecimientos en los tiempos modernos (1872), ed. española de 1942.

RICKERT, Ciencia cultural y ciencia natural, Ed. Espasa-Calpe, Col. Austral, n. ${ }^{\circ}$ 347, Buenos Aires, 1943.

32 Aranda a Roda, Madrid, 6 de mayo de 1766, AGS, GJ, leg. 1009, n. ${ }^{\circ} 227-8$. 
vantado en Tobarra contra 33 encausados por participar en el alboroto. Casi todos ellos coincidieron en decir que pasaban por allí -el lugar de mayor presión y vocerío-, estuvieron unos momentos movidos por la curiosidad y se fueron a su trabajo, pero no participaron, ni sabían nada de lo que allí había pasado ${ }^{33}$. Tuvieron que transcurrir algunos meses y hasta más de un año para que se abriesen los labios de algunos presos que mostraban su tranquilidad a otro compañero de cárcel porque su familia estaba bien atendida, o porque esperaba otro que cuando fuese nombrado Alcalde Mayor cierta persona saldría libre inmediatamente. El juramento de secreto para los altos y medios niveles fue completamente efectivo; solamente se constata como tal juramento en algunos testigos, como veremos en los del Alcalde del Crimen Felipe Musoles sobre los sucesos en la comarca alicantina.

\section{Los sucesos en la Gobernación de Alicante}

El temor y la reacción que el motín de Madrid produjo en Carlos III y en su gobierno tuvo alcances no reflejados suficientemente en la historiografía de su tiempo, es decir, en los manuscritos que se difundieron, y en la posterior. Me refiero al movimiento general de tropas que deberían concentrarse en torno a Madrid y Aranjuez. Las órdenes se dieron el día 25 de marzo a los Capitanes Generales de Galicia, Zaragoza, Barcelona, Valencia, Extremadura, Sevilla y Granada. El Capitán General de Valencia, D. Pedro Pablo Abarca de Bolea, la recibió el día 27 y con ella la primera noticia del motín matritense. Al día siguiente, viernes 28 , dio las órdenes para que salieran, con dirección a Aranjuez, dos Batallones de Infantería del Regimiento de Galicia y un escuadrón de Caballería de la Reina desde Valencia, otros tres de Caballería de la Reina desde Murcia, y a estas fuerzas se unirían el Regimiento de Infantería de Flandes, de guarnición en Alicante; el Regimiento de Dragones de la Reina, de guarnición en Orihuela; las fuerzas del Ejército en el Reino de Valencia quedaban reducidas a 50 hombres en Denia y otros 50 en Peñíscola, del Regimiento de Flandes, el Regimiento de Bruselas en Cartagena, necesario para la defensa del Arsenal y la custodia de los numerosos presos que trabajaban en él, 200 hombres en el Castillo de Alicante y 400 de artillería en Valencia. Dejó como Comandante General Interino al Teniente General D. Juan José Ladrón de Guevara, que era el Gobernador de Alicante; en Valencia, nombró al Mariscal de Campo Caballero de La Plain. Asimismo, el Regimiento de Guardias Valonas de Cataluña, que pasaría por la región valenciana

33 AHN, Cons., leg. 428, pieza 3, Declaración de testigos, ff. 4-37v. 
para reemplazar al de Valonas de Madrid, recibió orden de acelerar su marcha para unirse a los de Aranda en la ruta hacia Aranjuez. En la orden del 25 de abril se decía también a Aranda que se presentase al Rey, una vez llegado a Aranjuez, donde Aranda calculaba hallarse el miércoles 2 de abril. Sin embargo, los temores de la Corte se habían sosegado, pues el 26 se le decía que volviesen las tropas a sus lugares de origen. La nueva orden le llegó el 29 a Siete Aguas, a nueve leguas de Valencia. Las tropas regresaron el día 30, haciendo su camino por jornadas ordinarias, y Aranda siguió el suyo más despacio hacia Aranjuez, pero, por si el Rey decidía salir de Aranjuez, camino de Valencia, el Intendente de Valencia, Gómez de la Vega, debía tener dispuestos abastecimientos, etc., en la ruta de La Mancha pasando por Albacete ${ }^{34}$.

A partir de entonces fue señalándose el movimiento de agitación por la Península. El día 31 fue el motín de Tobarra, a nueve leguas de Cartagena, al siguiente día de pasar el Marqués de Esquilache con su comitiva para embarcar en este puerto para su destierro ${ }^{35}$. Desde el día $1 .^{\circ}$ de abril, martes, hasta el sábado 6 se sucedió la aparición de pasquines en Barcelona, Zaragoza, Salamanca, Granada, Valencia, Alicante, Cartagena y otros lugares. El domingo 6 fueron los primeros motines provinciales que con más pasquines se prolongaron durante todo el mes y el siguiente. En Valencia salió la caricatura recordada anteriormente y otro pasquín contra el Intendente-Corregidor Gómez de la Vega y su secretario Otero, «notado de muy interesado». Decía:

[Si quieres] que nadie tache / [tu] mal gobierno, Intendente / [da] provisión brevemente / sicut Squilace.

Otero es el Intendente / el Intendente Squilace, / la Ciudad Junta de Abastos. / Valencia y Madrid / qué enlace ${ }^{36}$.

El 8 de abril, el Tte. General Gobernador de Alicante informaba a D. Manuel Roda de los pasquines infamatorios fijados en Orihuela y en Cartagena contra los jefes de dichas ciudades y de otros subalternos; por ello providenció mayor resguardo de tropa para precaver escandalosos atrevimientos. El pueblo estaba tranquilo en Alicante, pero como la materia de escándalo eran los precios, había decidido, según el rumor que empezaba a oírse, rebajar el precio de la arroba de harina en cuatro sueldos y dos dineros y el del aceite en dos libras y quince suel-

34 Sobre las órdenes y la correspondencia de Aranda con Grimaldi, AGS, Sección Guerra Moderna, leg. 578, suplemento.

35 Vide C. E. CORONA, «Los sucesos de Tobarra...»

36 Archivo del Conde de Camponames, Fundación Universitaria Española, 47/7, fo- . lio 82. 
dos el cahíz, aunque sería con pérdida de dinero para el Pósito; y como el trigo existente en el Pósito se acabaría pronto, pedía permiso para valerse del existente en los almacenes que allí tenía Su Majestad. El mismo día, el Gobernador de Cartagena, Conde de Bolognino, escribía a don Manuel Roda de los pasquines y de sus medidas. Enviaba los dos últimos pasquines del día 7 :

Los moradores de esta Leal Ciudad piden forzosamente al Gobernador que los Víveres comestibles sean a mejor precio y de lo contrario será el mencionado Gobernador Quemado y Frito en Aceite hirviendo.

Mañana día 8 se vende este Pan en el horno del tío Basilio o en otro cualesquiera a ocho cuartos hecho de Agua y Harina. Se advierte al Público para que acudan a la hora del repartimiento de dicho Pan, que será desde las cinco de la mañana hasta las diez de la noche y habrá para todos y poca bulla.

Decía el Teniente General Ladrón de Guevara que éstos eran los ecos del pasado ruido en la Corte que se habían difundido. El Conde de Bolognino no se había andado con remilgos. Los libelos del día 7 eran la continuación de los anteriores y aún continuaron hasta el día 11 . Por propia decisión, el día 8 sacó los cañones a la calle y los situó mirando a la plaza donde estaban la cárcel y la Real Aduana; además había pedido a Ladrón de Guevara 200 soldados de Flandes y 80 caballos Dragones. Respecto de los precios, aun con pérdida de dinero para el Pósito, no los había bajado, sino que aumentó el peso desde $141 / 2$ onzas a 16 por el mismo precio de los 4 cuartos que costaban. El día 12 pidió que se le enviase completo el Batallón de Flandes para tener atendidos y con seguridad todos los servicios de la plaza ${ }^{37}$.

En Orihuela latían igualmente los rumores sobre la inquietud popular y los precios de los alimentos. El Gobernador político y militar de la ciudad, Coronel D. Felipe Caballero, con el regreso de los Dragones que habían salido por orden de Aranda, tomó sus medidas organizando patrullas de Caballeros Distinguidos, Labradores Honrados, Regidores y tropa, y dispuso ciertas rebajas en los precios. No se dio ninguna alteración de la tranquilidad, aunque se mantuvo una atención vigilante ${ }^{38}$.

El Rey aprobó las rebajas de precios acordadas por el Gobernador

37 Ladrón de Guevara a Roda, Alicante, 8 de abril de 1766, AGS, G.J leg. 1009, núms. 506-509. Bolognino a Grimaldi, Cartagena, 8 de abril, con copia de los pasquines enviados el 10 a Ladrón de Guevara, y 12 de abril de Bolognino a Crimaldi, de Ladrón a Grimaldi, 12 de abril, todos en AGS, Guerra Moderna, 578, suplemento, sin foliar.

38 Ladrón de Guevara a Grimaldi, Alicante, 12 de abril, AGS, GM, 578, suplemento, Arch. Municipal de Orihuela, Ac. cap., 1766, 6 al 22 de mayo. Me complace agradecer aquí los datos de Orihuela a la amabilidad del Prof. de la Universidad de Mureia Dr. Joaquín Ruiz Alemán. 
de Alicante. El Secretario de Gracia y Justicia, don Manuel Roda lo comunicó al Conde de Aranda, Presidente del Consejo de Castilla desde el día 9, aclarando que los magistrados no estaban obligados a mantener las bajas de precios pues tampoco tenían facultades, que correspondían al Rey, para alterarlos. El informe de los fiscales al Consejo del 23 de abril sobre esta cuestión se convirtió en el Auto Acordado del 5 de mayo restableciendo los precios que se habían modificado por las autoridades locales. Sin embargo, hasta este día, siguió como aceptable que no se debía desaprobar lo que los magistrados habían hecho para mantener la quietud en los pueblos, por urgencia y necesidad, «de otra forma no puede haber la debida seguridad de que se extinga el fuego y vuelva de nuevo á encenderse» ${ }^{39}$. Bolognino ofreció premios de $50 \mathrm{y}$ 100 doblones al que delatase o prendiese a los que pusiesen pasquines. También convocó a cuatro compañías de 60 hombres de las Milicias Urbanas para tenerlas acuarteladas, pero, suspendió la orden por el anuncio de la tropa pedida a Alicante. En su opinión, prefería las Milicias Provinciales a las Urbanas, pues las Provinciales estaban mandadas por oficiales, sargentos y veteranos del Ejército y celebraban dos veces al año asambleas de instrucción ${ }^{40}$.

En realidad, el gran movimiento que con expresa cautela no puede llamarse subversivo, porque fue grito común en todos los lugares, «Viva el Rey y abajo el mal gobierno», se desarrolló en los siguientes lugares:

Domingo 13, a las nueve de la mañana, en el Arrabal de San Juan, municipio distinto de Elche, donde continuó por la tarde, señorío del Duque de Arcos

Lunes 14, Almoradí, a las siete de la tarde, lugar de realengo

Jueves 16, Catral, lugar de realengo

Domingo 20, a las once de la mañana, Crevillente, del señorío de Arcos; Novelda, señorío del Marqués de la Romana

Lunes 21, Albatera, del señorío del marquesado de Dos Aguas

Martes 22, Castillo de Santa Pola, del señorío de Arcos.

La situación creada por los tumultos se mantuvo hasta el 5 de mayo, en que se restableció la situación anterior.

Queda indicado que Almoradí y Catral eran lugares de realengo.

Minuta de Roda a Aranda de abril. de 1766, AGS, GJ, leg. 1009, n. ${ }^{\circ} 193$.

Bolognino a Grimaldi, Cartagena, 15 de abril de 1766, AGS, GM, 578, suplemento. 
El estudio de Mariano Peset y Vicente Graullera sobre los señoríos valencianos ${ }^{41}$ ofrece algunos datos sobre los lugares afectados:

El Marqués de Elche, Duque de Arcos, Duque de Maqueda, duque de Nájera y marqués de Astorga, era en 1751 don Francisco Ponce de León. Su señorío valenciano comprendía: Elche, cuyo término tenía una población de 16.030 habitantes, Crevillente, Almudaina, Aspe, Benialfaquí, Catamar, Margarida, Patraix y Planes, con una población total de 33.597 habitantes. Tenía bajo sus armas el Castillo de Santa Pola.

El condado de Albatera había pertenecido (1750) a don Ginés Ramón Rabasa Perellós Lanuza Rocafull-Boil, pero en la fecha que consideramos las referencias se hacen a la Marquesa. El señorío valenciano lo formaban: Albatera, Benetúser, Benicolet, Bétera, Castalla, Chirivella, Dos Aguas, Fuente la Higuera, La Daya, Luchente, Masamagrell, Masanasa, Onil, Picasent, Pinet, Quatretonda y Tibi, con una población de 21.011 habitantes.

La baronía de Novelda, con la de Mogente y el marquesado de La Romana, pertenecía (1754) a don Pedro Maza de Lizana, con una población de 8.854 habitantes.

La agitación padecida por Elche y pueblos circunvecinos se extendió temporalmente desde el 13 de abril hasta el 10 de mayo, fecha en que el Comisionado por la Audiencia de Valencia, don Felipe Musoles, comunicó que se había restablecido enteramente y en todos los aspectos la situación anterior ${ }^{42}$. Las dos monografías que examinan los hechos ocurridos en la región alicantina han dado dos perspectivas: Palop la expresa en el título «Hambre y lucha antifeudal»; Ruiz Torres, no acepta enteramente las opiniones de Palop y se inspira y sigue a P. Vilar para entenderlos como «típicas revueltas populares espontáneas en una sociedad agraria en crisis», o, en otras palabras, resultado manifiesto del cambio de estructuras en la sociedad del Antiguo Régimen. Palop no llega a convencer respecto del «hambre», si afirma que en la región valenciana «en todo momento hubo una relativa abundancia de trigo» ${ }^{43}$. Por otra parte, el desarrollo económico peninsular durante la primera mitad del siglo XVIII, así como el de la población, parece claro y debe ser estudiado sin condicionamientos apriorísticos; parece más

41 «Nobleza y señoríos durante el siglo XVIII valenciano», en Estudios de Historia Social, núms. 12-13, 1980, pp. 245-281.

42 Musoles a Aranda, 10 y 13 de mayo de 1766, AHN, Cons., leg. 22625/20.

43 Obras citadas de PALOP y RUIZ TORRES, pp. 97 y 53, respectivamente. 
claro - y muy necesitado de investigaciones no condicionadas- durante la segunda mitad, sin que se insista en problemas de luchas de clases que tan sólo atisbaban algunos escritores de la Ilustración política. No son éstos, sin embargo, los temas de estas líneas; pueden ser materia de debate que dejo al margen.

Debemos admitir como incuestionables los efectos de la carestía, por la serie de cosechas deficientes, sobre la constante inflación de los precios en toda España, con niveles muy diferentes, y también la reacción antifeudal en esta comarca levantina. La singularidad de esta característica llevada hasta considerarla como razón sobresaliente de los motines se ofrece con carácter oportunista. En cada lugar se busca un motivo propio. Se han recordados los Vítores de Badajoz y de Baza y pueden añadirse otros; en Burgos, por ejemplo, la inquietud se iba arremolinando en torno a las disposiciones del Obispo para la provisión de beneficios eclesiásticos, pero las bajas de precios y otras medidas sofocaron el motín. El planeamiento mejor de un motín se dio en Jaén, donde se redujo sin razón el abastecimiento de pan en el mercado popular para provocar los gritos airados, etc., etc.; era el recurso perfecto para provocar la espontaneidad de la algarada.

Ateniéndonos a la cuidadosa narración cronológica de Palop y de Ruiz Torres sobre los motines de Elche y comarcanos, parece que éstos no tuvieron relación con los contemporáneos peninsulares. Ahora bien, puede confirmarse la aseveración respondiendo a las siguientes cuestiones observadas en el resto de España: si fueron realmente tumultos espontáneos, si hubo preparación previa mediante pasquines y si éstos responden a la misma temática, si hubo equipos de dirección y de preparación de las algaradas, si fue el pan el motivo primero y principal, si se halla alguna relación con algunos artículos de las Constituciones y Ordenanzas del llamado Cuerpo Nacional o Militar, si el enfrentamiento del Ejército con los tumultuados causó víctimas y sangre.

El movimiento se inició a las nueve de la mañana del día 13 de abril en el Arrabal de San Juan, cuyo cabildo, distinto del de Elche, procedía a las subastas de regalías y derechos señoriales del Duque de Arcos. La concurrencia de gentes era grande; nadie pujaba y la subasta se demoraría hasta el día siguiente, pero se levantó la voz de un jornalero del campo, Bautista Blasco, «el Venerable Viejo», de 56 años, hombre de buen concepto y pobre, que, en nombre del Común, se declaró contrario a cualquier subasta. Fue aclamado y tras un cambio de palabras con el Procurador Síndico don Ricardo Sánchez, acusado de «Esquilache», comenzó la revuelta antiseñorial a los gritos de «Viva el Rey, muera el Duque de Arcos y don Ricardo Sánchez, segundo Esquilache». En la 
tarde del mismo domingo la concentración de gentes renovó el caso en el mismo Elche, y el lunes 14 y el jueves 15, en Almoradí y en Catral, respectivamente, lugares de realengo. El domingo siguiente, 20, prosperó la acción hasta el martes en los señorios de Crevillente, Novelda, Albatera, señoríos de Arcos, Marqués de la Romana y marquesado de Dos Aguas; el 22 fue el asalto al Castillo de Santa Pola, del Duque de Arcos. Con la excepción de los dos lugares de realengo, el movimiento se dirigió contra el régimen feudal, si bien el clamor tuvo especial virulencia contra el Duque de Arcos.

El Duque de Arcos resultó tildado de la severa opinión expresada, según se decía, en el Consejo de Guerra reunido por Carlos III en la tarde del 23 de marzo para conocer la opinión de sus altos Generales ante la conmoción madrileña. Fueron éstos: el Duque de Arcos, Teniente General y Capitán de la $1 .^{a}$ Compañía de Reales Guardias de Corps; el Conde de Gazola, Comandante General de la Artillería; el Conde de Priego, Teniente General y Coronel del Regimiento de Guardias Walonas; el marqués de Sarriá, Teniente General y Coronel del Regimiento de Reales Guardias Españolas; el Conde de Oñate, Mayordomo Mayor del Rey, sin empleo militar, y el Conde de Revillagigedo, Capitán General y Presidente del Consejo de Guerra ${ }^{44}$. El resultado de la reunión se difundió como la transcripción, al pie de la letra, de un acta con las palabras pronunciadas por cada uno de los asistentes. La opinión de Arcos fue dura: represión violenta, según ese texto, quizá resultado de su enfrentamiento personal con los amotinados en las calles de Madrid; los dos siguientes, cuyos soldados fueron víctimas de feroces agresiones, se sumaron a su voto; los otros tres fueron partidarios de la piedad y a su opinión se sumó el Rey. Nadie ha podido dar la procedencia legítima y autorizada de la versión de este Consejo de Guerra; sin embargo, se difundió y ha quedado como válida en todos sus términos y sirvió para constrastar el criterio del vitoreado Carlos III «con las cotas inhumanas de su lacayo» el Duque de Arcos, aceptadas por Palop. No hay dudas de que la mala propaganda contra Arcos tuvo efectos. El informe de los fiscales sobre lo ocurrido en Elche, el 21 de abril, dice: «que este asunto no deja de ser sumamente grave por sus circunstancias y digno de mirarse con particular atención por resultas de los pasquines publicados en la Corte contra el acreditado mérito de la Casa de Arcos y su actual poseedor». El Superintendente de Correos don Lázaro Fernández de Angulo, en sus noticias a Roda sobre el ambiente de Madrid,

44 Textos del llamado Consejo de Guerra se encuentran en los manuscritos citados en la nota 1 y en el Arch. C. Campomanes, 47/3 y 47/7, donde hay varias copias, todas con ligeras variantes. 
le trasmitía los lamentos de una mujerzuela enfurecida cuya hermana y su hija habían muerto en el Hospital por la Patria y añadía: «No me quite Dios la vida hasta que yo se la quite a un pícaro traidor, [...] ese pícaro traidor del Duque de Arcos que dio orden de disparar contra la Gente el día del motín ${ }^{45}$. Las murmuraciones en Madrid no eran sólo contra Arcos, cuyo palacio decían habían quemado en Elche «por haberse inclinado al partido de los italianos», sino contra Gazola, Sabatini y las Marquesas de Salvatierra y Tordesillas, desterradas de Madrid $^{46}$. Por esto, está dentro de lo posible el castigo de Arcos en su señorío, donde existía una tensión antigua motivada por pleitos con sus vasallos. No se aprecia igual animosidad contra La Romana, ni contra la Marquesa de Dos Aguas, de la que se reclamaban los títulos de legítima posesión de sus derechos, de acuerdo con la política real de incorporación de señoríos y alhajas de la Corona, estudiada por Moxó ${ }^{47}$.

Aunque las asonadas alicantinas tienen como objetivo directo la abolición del sistema señorial suprimiendo el régimen de arbitrios y derechos señoriales, símbolos, etc., lo que aparece invariablemente es la rebaja del precio del pan, del vino y de otros comestibles. Consecuentemente, lo mismo que en los pasquines de toda la península, se encuentra el pan en los conocidos y en los publicados por Palop. El de Crevillente era éste:

Tiendas se han de quitar, y al que arrancare estos papeles

las manos se le han de cortar

\section{Y el de Albatera:}

Todo principio tiene fin. / Sólo la ley de Dios. / Atención, que digo lo que es de razón. Ese padastro del vino que hay en la tienda no / es razón que los pobres lo padezcan por complacer al Señor; / en días pasados se publicó un Despacho de Su Magestad / sobre nuevos impuestos, no se obedeció, / si no se pone remedio se dará cuenta al superior; / Como la carga del molino, / los pobres harineros van a traer trigo a Alicante, / y que por fuerza lo hacen

45 AHN, Cons., leg. 22625, n. ${ }^{\circ}$ 20, Madrid, 21 de abril, con las rúbricas de los dos fiscales. Lázaro Fernández a Roda, 22 de abril de 1766, AGS, GJ, 1009, 550-552. PALOP reproduce una décima satírica, muy divulgada contra Arcos, en su o. c., p. 135, tomada del AGS, GJ, n. ${ }^{\circ} 581$, de una carta que «va sin firma por si acaso la cogen».

46 Anónima sin fecha, interceptada, Arch. C. Campomanes, 47/7, ff. 14-15.

47 Salvador de MOXO, La incorporación de señoríos en la España del Antiguo Régimen, Valladolid, 1959, completada con Disolución del régimen señorial en Espa$\tilde{n} a$, Madrid, C. S. I. C., 1965. 
venir a este molino, / esa carestía de pan sobre ese cargamento que habéis consentido / por complacer al Señor, / que se ponga remedio, y, si no, se dará cuenta a Su Magestad, / y si lo defiende el escribano se le dará del pan y del palo. / Esto lo manda el común. / Muera Pascual Valero Esquilase que enriquese al Marqués y al panadero plase. / A Pascual Valero cortarle la cabeza primero / otro pájaro queda en el rincón / que tira la piedra y esconde la mano y se queda en salvación. Catón ${ }^{48}$.

No hay diferencias: el pan, el que Palop llama «acólito» del Marqués de Dos Aguas, su cómplice o beneficiario, Esquilache y la amenaza de muerte. Los gritos en los tumultos eran asimismo coincidentes: «iViva el Rey! ¡Muera el mal gobierno!», con las variantes acomodadas en cada pueblo, «iMuera el Duque de Arcos, muera el gobierno de los Pelucas, el segundo Esquilache don Ricardo Sánchez!», en Elche; « $V$ Viva el Rey y muera la Marquesa de Dos Aguas y el mal gobierno!», en Albatera, etc. ${ }^{49}$. ¿A qué superior se refiere el pasquín de Albatera? ¿Sería el mismo que el que ordenaba a Villena, en Madrid?

La idea gratuitamente esparcida sobre la espontaneidad de los motines se disipa fácilmente con leer los procesos incoados por el Oidor Felipe Musoles y las sentencias aplicadas a los procesados, depurando las responsabilidades desde los primeros relatos de los sucesos. En Elche se calificaron como capataces o cabezas del motín a cuatro: $1 .^{\circ}$, el abogado Dr. José Beltrán Esclapés, en cuyo favor un certificado médico recogido en el caso de Crevillente dice padecer «una especie de delirio melancólico que le acompaña muchos años con ligereces que manifiestan la debilidad de su juicio con manía espiritual» (o especial); tenía 69 años y había sido Alcalde (cargo de Justicia) y Regidor; realmente fue quien aportó la doctrina antifeudal y redactó bandos, disposiciones y programas para el nuevo régimen de Elche y de Crevillente, incorporados a la Corona Real. Como activos y voceros en las calles, Musoles calificó a Bautista Blasco, «el Venerable Viejo»; a Francisco Romero, «el Botí», de 47 años, maestro zapatero, que «embarazó para que no quemasen la casa de D. Francisco Antón», y José Vázquez, jornalero del campo, juzgado en ausencia. Por declaraciones de testigos parece

PALOP, o. c., pp. 157 y 160-161. El subrayado es mío.

49

Ladrón de Guevara a Grimaldi, Alicante, 15 de abril de 1766, AGS, GM, leg. 578 , suplemento. AHN, Cons., leg. 22625, n. ${ }^{\circ} 19$, Procesos, Resultancia del Ramo Once de la presente causa contra María Pimental; la Villa al Rey, 13 y 15 de abril, en el n. ${ }^{\circ} 20$ del mismo legajo; Auto del escribano de Valencia José Vicente Entraygues, Elche, 17 de junio. Respecto de Crevillente, cuatro Regidores, el Síndico General y el Tte. de Gobernador, Crevillente, 28 de abril, en el mismo leg. n. ${ }^{\circ} 5$. En Albatera, extracto de Musoles del 7 de marzo de 1767 , en el mismo leg. $n .{ }^{\circ} 18$. 
ser que en la casa de «el Botí» se reunían los cuatro capitanes para la preparación del motín, cuyo anuncio previo otro testigo atribuyó a Romero y a otro acusado, Vaquero; tres o cuatro días antes, en una discusión sobre precios, «prorrumpieron con enfado y altas voces de que antes de muchos días se pondría remedio». Sebastián Adsuar, «el Diablillo», procesado n..$^{\circ} 19$ en los de Elche por Musoles, fue a comprar días antes del tumulto media libra de arroz y quiso se la dieran por 6 dineros, pero se lo resistían y dijo que no pasaría mucho sin que se quitasen los abastos, y sería todo libre y no pagarían arriendos, etc., y se jugó un doblón y luego lo reclamó al tendero. La noticia se la dio el Dr. José Beltrán Esclapés y le amenazó con quitarle el pellejo si lo decía. En Elche fueron depuestos los Justicias, el Alcalde Mayor, Tomás Andrés Gusema, y los dos Ordinarios el 13 por la tarde, pero volvió a nombrarse al segundo Alcalde Ordinario, Jaime Alamo, por el Rey; se mostró tolerante, moderado y pasivo en los restantes días del tumulto, con escándalo para los fiscales del Consejo. En cartas anónimas se denunciaba al Duque de Arcos la complicidad de Alamo.

En Crevillente, el Teniente Gobernador y los Regidores declararon cooperadores del tumulto a los dos Alcaldes, José Fuentes y Antonio Sánchez, bajo la dirección del abogado Beltrán Esclapés. En Catral, a las siete de la tarde fue el asalto al Ayuntamiento, con los capitulares reunidos, por tres embozados y armados, de los cuales solamente fue apresado uno. Los tres organizaron la gritería y aseguraron que tenían más gente que les acompañaba. Como en Almoradí, donde los testimonios de Pedro Sánchez de Pastor contra los inculpados Hernández, de familia acomodada y propietarios, y contra Diego Lechuga, denuncian que había grupos de inductores que guardarían las espaldas. Las gentes del común «no eran capaces por sí solos [...] de no habérselo aconsejado otros» de la algarada, llevada en todo momento con un orden eficaz. «No hubieran hecho semejantes excesos, por ser unos pobres, a no ser que los Poderosos se los hubieran aconsejado y como les necesitan para que les den a ganar un jornal, ciegamente y sin reflexión operaron aquello mismo que les dijeron». En Almoradí fueron procesados seis eclesiásticos, uno ordenado de menores, que concurrieron a las reuniones preparadoras del tumulto, estaban inteligenciados y fueron calificados de fomentadores del motín recomendando que guardasen silencio sobre lo que habian oído. Cuatro Regidores de Almoradí fueron apercibidos por la sentencia del Consejo. En Albatera, el «mandón y capitán» pareció ser Manuel Alcarrás, de 28 años, casado y jornalero, pero fue instigado por D. Tomás Martínez, Familiar del Santo Oficio, «que no podía sacar la cara y por ello le hicieron jurar que guardaría secre- 

Albero ${ }^{50}$.

La última observación que podemos hacer sobre los sucesos de la Gobernación de Alicante debe referirse al comportamiento del Ejército. No difiere en cuanto a pasividad del observado en otras partes, salvo en Guipúzcoa. A pesar de la inquietud que Ladrón de Guevara manifiesta en sus comunicaciones a Grimaldi, el Ejército tan sólo intervino cuando Don Felipe Musoles tuvo a su disposición a dos Compañías de Infantería y 20 Dragones de Caballería desde el 28 de abril, fecha en que se trasladó a Elche. Llama la atención que cuando el 22 fuerzas armadas de Elche y Crevillente se dirigieron al Castillo de Santa Pola para quitarlo de la obediencia al duque de Arcos y ponerlo bajo la autoridad directa del Rey, el Alcaide del Castillo, Sargento Pascual Ortiz, no opuso resistencia alguna. Entregó el mando al «Motín» - como en Madrid, el «Motín» adquiere una especie de personalidad jurídica incontrovertida - mansamente y volvió a recibirlo inmediatamente dando su juramento al Rey. El Alcaide Ortiz fue procesado; sin embargo, la condena se redujo a pagar las costas del proceso y a ser apercibido.

Bajo el mando directo de Musoles, las fuerzas a sus órdenes tuvieron dos actuaciones. La primera fue para el apresamiento de siete inculpados, el 3 de mayo, refugiados en el Convento franciscano de San José. La tropa no desempeñó otro papel que el de reserva, pues previamente había dispuesto un alistamiento general de "gente de honor», prevenidos con armas, que a las once de la noche del día 3 apresaron a Beltrán Esclapés y a los restantes. Asegurados con grillos y suficiente tropa, los siete fueron conducidos al Castillo de Alicante. No fue éste el último episodio. El día 8, entre cuatro y cinco de la tade, el «Motín», otro movimiento de los malcontentos, obligó a reunir a los nobles y gente honrada, alistados por Musoles, con la Infantería y los 20 Dragones. Pretendían liberar a los siete presos en Alicante; eran pocos cientos armados. Ante la Infantería quedaron contenidos, después cargó la Caballería a toda brida y el intento de liberación se disolvió «sin la menor desgracia». El intento bien podría relacionarse con el artículo 6 de las «Constituciones y Ordenanzas» del Militar Cuerpo.

A partir del día 10 de mayo el sosiego quedó restablecido; la agitación antiseñorial quedó soterrada. Musoles se dedicó a los sumarios,

50 Los relatos de los motines, los testimonios, extractos de Musoles y las sentencias se encuentran reunidos en AHN, Cons., leg. 22625, con la numeración que se da a continuación separadamente para cada uno de los lugares: núms. 4, 13 y 16 para Almoradí; núms. 5, 10, 12 y 17 para Crevillente; núms. 7 y 18 para Albatera; núm. 14 para Catral; núms. 3, 6, 9, 11, 15 (extracto y sentencia), 19 y 20 para Elche. 
cuyas resoluciones se prolongaron durante un año. El día 13 escribía al Fiscal del Consejo Rodríguez Campomanes: "Confidencialmente estoy informado que los dos Alcaldes de aquel Pueblo [Crevillente] en mucha parte son culpados en sus Alborotos. Algo tengo ya justificado y confío ponerlo en claro con la pesquisa». El día 27 confiaba a Peñuelas, de la Secretaría del Consejo: «Los culpados le hacen recelar haber ocurrido motores o auxiliadores del motín de mayor esfera que la que tienen los presos de Alicante. Cuando lo descubra dará cuenta» ${ }^{51}$.

No sabemos si D. Felipe Musoles descubrió algo más de lo que figura en las sentencias; sin embargo, los hechos con su evidente tendencia antifeudal no pueden aislarse de los que en los mismos días se sucedían en la Península. Si hubo conspiradores de altas esferas, de su presunta acta de conspiración tan sólo sabemos lo que se desprende de las Constituciones y Ordenanzas, de la Humilde Representación al Rey y de las protestas políticas contenidas en los pasquines presentados como la voz del común para pedir la rebaja de los precios de los abastecimientos.

51 Del mismo día 10 de mayo de 1766, los Diputados de la nobleza de Elche y de Felipe Musoles a Aranda; oficio de Musoles a Aranda del 5 de mayo en legajo citado ut supra, $\mathrm{n} .{ }^{\circ} 20$. Sobre la declaración del acusado de Albatera contra el Familiar del Santo Oficio, n. ${ }^{\circ} 18$ del mismo legajo. 